\title{
The effect of kidney function on the urate lowering effect and safety of increasing allopurinol above doses based on creatinine clearance: a post hoc analysis of a randomized controlled trial
}

Lisa K. Stamp ${ }^{1,2^{*}}$, Peter T. Chapman ${ }^{2}$, Murray Barclay ${ }^{1}$, Anne Horne $^{3}$, Christopher Frampton ${ }^{1}$, Paul Tan ${ }^{3}$, Jill Drake ${ }^{1}$ and Nicola Dalbeth ${ }^{3}$

\begin{abstract}
Background: The use of allopurinol in people with chronic kidney disease (CKD) remains one of the most controversial areas in gout management. The aim of this study was to determine the effect of baseline kidney function on safety and efficacy of allopurinol dose escalation to achieve serum urate (SU) $<6 \mathrm{mg} / \mathrm{dl}$.

Methods: We undertook a post hoc analysis of a 24-month allopurinol dose escalation treat-to-target SU randomized controlled trial, in which 183 people with gout were randomized to continue current dose allopurinol for 12 months and then enter the dose escalation phase or to begin allopurinol dose escalation immediately. Allopurinol was increased monthly until SU was $<6 \mathrm{mg} / \mathrm{dl}$. The effect of baseline kidney function on urate lowering and adverse effects was investigated.
\end{abstract}

Results: Irrespective of randomization, there was no difference in the percentage of those with creatinine clearance $(\mathrm{CrCL})<30 \mathrm{ml} / \mathrm{min}$ who achieved SU $<6 \mathrm{mg} / \mathrm{dl}$ at the final visit compared to those with $\mathrm{CrCL} \geq 30$ to $<60 \mathrm{ml} / \mathrm{min}$ and those with $\mathrm{CrCL} \geq 60 \mathrm{ml} / \mathrm{min}$, with percentages of $64.3 \%$ vs. $76.4 \%$ vs. $75.0 \%$, respectively $(p=0.65)$. The mean allopurinol dose at month 24 was significantly lower in those with $\mathrm{CrCL}<30 \mathrm{ml} / \mathrm{min}$ as compared to those with $\mathrm{CrCL} \geq 30$ to $<60 \mathrm{ml} / \mathrm{min}$ or $\mathrm{CrCL} \geq 60 \mathrm{ml} / \mathrm{min}$ (mean (SD) 250 (43), 365 (22), and 460 (19) mg/day, respectively ( $p<$ $0.001))$. Adverse events were similar among groups.

Conclusions: Allopurinol is effective at lowering urate even though and accepting that there were small numbers of participants with $\mathrm{CrCL}<30 \mathrm{ml} / \mathrm{min}$, these data indicate that allopurinol dose escalation to target $\mathrm{SU}$ is safe in people with severe CKD. The dose required to achieve target urate is higher in those with better kidney function.

Trial registration: Australian and New Zealand Clinical trials Registry, ACTRN12611000845932. Registered on 10 August 2011.

Keywords: Allopurinol, Chronic kidney disease, Gout, Serum urate

\footnotetext{
*Correspondence: lisa.stamp@cdhb.health.nz

'Department of Medicine, University of Otago, Christchurch, P. O. Box 4345,

Christchurch 8140, New Zealand

${ }^{2}$ Department of Rheumatology, Immunology and Allergy, Christchurch

Hospital, Private Bag 4710, Christchurch 8140, New Zealand

Full list of author information is available at the end of the article
} 


\section{Background}

The use of allopurinol in people with chronic kidney disease (CKD) remains one of the most controversial areas in gout management. While recommendations from the American College of Rheumatology (ACR) [1] and European League Against Rheumatism (EULAR) [2] both advocate allopurinol as a first-line urate lowering therapy (ULT), for dosing guidance the ACR advocates a gradual dose escalation even in those with CKD [1], while EULAR recommends dose restriction based on creatinine clearance $(\mathrm{CrCL})$ [2]. This discrepancy is due to concerns over increased risk of adverse effects, particularly allopurinol hypersensitivity syndrome (AHS) and limited data on the use of allopurinol in CKD.

Since the initial allopurinol dosing guidelines by Hande et al., based on an association between allopurinol dose, oxypurinol and AHS, were published [3], a number of other risk factors for AHS have been identified [4]. The Hande dosing strategy does not differentiate between starting dose, which has been associated with AHS [5], and maintenance dose (i.e. dose required to achieve target serum urate (SU)). Once AHS occurs, people with CKD have higher mortality [6].

Clinical trials of ULT have excluded those with significant CKD and restricted the allopurinol dose to $\leq$ $300 \mathrm{mg}$ daily even in those with normal kidney function [7-9]. We have previously reported results from a randomized controlled trial of allopurinol dose escalation to achieve target urate in which $52 \%$ of the 183 participants had $\mathrm{CrCL}<60 \mathrm{ml} / \mathrm{min}$, suggesting that such an approach is effective and safe [10]. Herein we undertook a post hoc analysis to determine the effect of baseline kidney function on the safety and efficacy of the allopurinol dose escalation strategy.

\section{Methods}

\section{Study design}

A 24-month open, randomized, controlled, parallelgroup, comparative clinical trial was undertaken (ACTRN12611000845932). Ethical approval was obtained from the Multi-Regional Ethics Committee, New Zealand. Written informed consent was obtained from each participant. Full methods have been reported previously $[10,11]$. In brief, 183 people with gout as defined by the American Rheumatism Association 1977 preliminary classification criteria for gout [12], receiving at least the $\mathrm{CrCl}$ based dose of allopurinol for $\geq 1$ month and with $\mathrm{SU} \geq 6 \mathrm{mg} / \mathrm{dl}$ were recruited. People with a history of intolerance to allopurinol and those receiving azathioprine were excluded. Chronic kidney disease was not an exclusion criterion. Participants were randomized to continue current dose allopurinol for 12 months and then enter the dose escalation phase (control/DE) or to begin allopurinol dose escalation immediately (DE/DE).
Allopurinol was increased monthly until SU was $<6 \mathrm{mg} /$ $\mathrm{dl}$; in those with $\mathrm{CrCL} \leq 60 \mathrm{ml} / \mathrm{min}$ allopurinol was increased by $50 \mathrm{mg}$ increments and in those with $\mathrm{CrCL}$ $>60 \mathrm{ml} / \mathrm{min}$ it was increased by $100 \mathrm{mg}$. Participants were not stratified by renal function at randomization. For the purposes of this post hoc analysis, participants were grouped according to kidney function at baseline as having (1) none/mild impairment, $\mathrm{CrCL} \geq 60 \mathrm{ml} / \mathrm{min}$ (CKD stage 1 and 2), (2) moderate impairment, $\mathrm{CrCL}$ $\geq 30$ to $<60 \mathrm{ml} / \mathrm{min}$ (CKD stage 3 ) and (3) severe impairment, $\mathrm{CrCL}<30 \mathrm{ml} / \mathrm{min}$ (CKD stage 4 and 5 ).

\section{Adverse and serious advent event reporting}

Treatment-emergent adverse events (AE) were defined as any $\mathrm{AE}$ occurring after entry into the study until the end of month 24. Worsening laboratory-defined AEs were those where there was an increase in $\mathrm{AE}$ grade from baseline between month 12 and month 24, using the Common Terminology Criteria for Adverse Events (CTCAE v4.0).

\section{Study outcomes}

The primary efficacy outcome was reduction in SU at the final visit (month 24 or the final visit for those deceased or lost to follow up). Secondary efficacy outcomes included (1) the proportion of participants reaching target SU levels from baseline to months 12 and 24 and from months 12 to 24, (2) the percentage reduction in SU from baseline to months 12 and 24 and from months 12 to 24 and (3) the dose of allopurinol required to achieve $\mathrm{SU}<6 \mathrm{mg} / \mathrm{dl}$. The primary safety outcome was serious adverse events (SAEs) and treatmentemergent or worsening AEs related to liver or kidney function.

\section{Statistical analysis}

Baseline demographics and clinical features were summarized using standard descriptive statistics including mean, standard deviation (SD), range, frequency and percent as appropriate.

Changes from baseline to months 12 and 24 and from month 12 to month 24, and levels at 12 and 24 months were compared between kidney function groups using analysis of variance (ANOVA), which included the randomized group and the interaction between the randomized group and kidney function groups as factors. Comparisons of baseline levels were compared using one-way ANOVA, which only included kidney function group as the factor. Dichotomous outcome measures were compared using logistic regression, which included $\mathrm{CrCL}$ and randomized group and the interaction between the randomized group and kidney function groups as factors. A two-tailed $p$ value $<0.05$ was taken to indicate statistical significance. 
Table 1 Participant baseline demographics and clinical features

\begin{tabular}{|c|c|c|c|c|c|c|}
\hline \multirow[t]{2}{*}{ Variable } & \multicolumn{3}{|c|}{ Control/dose escalation $(n=93)$} & \multicolumn{3}{|c|}{ Dose escalation/dose escalation $(n=90)$} \\
\hline & $\begin{array}{l}\mathrm{CrCL}<30 \mathrm{ml} / \\
\min (n=14)\end{array}$ & $\begin{array}{l}\mathrm{CrCL} \geq 30 \text { to }<60 \mathrm{ml} / \\
\min (n=31)\end{array}$ & $\begin{array}{l}\mathrm{CrCL} \geq 60 \mathrm{ml} / \\
\min (n=48)\end{array}$ & $\begin{array}{l}\mathrm{CrCL}<30 \mathrm{ml} / \\
\min (n=10)\end{array}$ & $\begin{array}{l}\mathrm{CrCL} \geq 30 \text { to }<60 \mathrm{ml} / \\
\min (n=40)\end{array}$ & $\begin{array}{l}\mathrm{CrCL} \geq 60 \mathrm{ml} / \\
\min (n=40)\end{array}$ \\
\hline Age years ${ }^{a}$ & $68.2(14.2)$ & $66.6(9.3)$ & $54.8(11.9)$ & $66.8(12.5)$ & $64.6(9.6)$ & $52.5(12.1)$ \\
\hline Male, $n(\%)$ & $7(50 \%)$ & $25(80.6 \%)$ & $46(95.8)$ & $9(90 \%)$ & $34(85 \%)$ & $39(97.5)$ \\
\hline \multicolumn{7}{|l|}{ Ethnicity, n (\%) } \\
\hline NZ European & $6(42.9 \%)$ & $13(41.9 \%)$ & $20(41.7 \%)$ & $2(20 \%)$ & $21(52.5 \%)$ & $14(35 \%)$ \\
\hline Maori & $3(21.4 \%)$ & $10(32.3 \%)$ & $9(18.8 \%)$ & $3(30.0 \%)$ & $13(32.5 \%)$ & $13(32.5 \%)$ \\
\hline Pacific Island & $4(28.6 \%)$ & $6(19.4 \%)$ & $17(35.4 \%)$ & $5(50 \%)$ & $5(12.5 \%)$ & $9(22.5 \%)$ \\
\hline Asian & $1(7.1)$ & $2(6.5 \%)$ & $1(2.1 \%)$ & $0(0 \%)$ & $1(2.5 \%)$ & $4(10.0 \%)$ \\
\hline Other & $0(0 \%)$ & $0(0 \%)$ & $1(2.1 \%)$ & $0(0 \%)$ & $0(0 \%)$ & $0(0 \%)$ \\
\hline Duration of gout (years) & $16.8(14.8)$ & $18.2(14.7)$ & $18.1(11.9)$ & $13.1(11.2)$ & $16.9(11.2)$ & $16.9(11.2)$ \\
\hline $\begin{array}{l}\text { Baseline serum urate } \\
\mathrm{mg} / \mathrm{dl}^{\mathrm{a}}\end{array}$ & $8.3(1.5)$ & $7.1(1.6)$ & $6.8(1.5)$ & $8.0(1.6)$ & $7.6(1.6)$ & $6.5(1.3)$ \\
\hline $\mathrm{CrCL}(\mathrm{ml} / \mathrm{min})$ & $19.8(5.9)$ & $44.3(7.9)$ & $82.4(16.6$ & $21.1(6.7)$ & $44.5(8.1)$ & $85.5(17.7)$ \\
\hline $\begin{array}{l}\text { Body mass index }(\mathrm{kg} / \\
\left.\mathrm{m}^{2}\right)^{\mathrm{a}}\end{array}$ & $34.6(7.2)$ & $35.8(8.3)$ & $35.1(7.5)$ & $36.9(8.4)$ & $35.9(8.4)$ & $33.7(6.8)$ \\
\hline $\begin{array}{l}\text { Baseline allopurinol dose } \\
\mathrm{mg} / \text { day }^{\mathrm{b}}\end{array}$ & $135.7(100-250)$ & $258.1(150-400)$ & $328.1(200-600)$ & $160.0(100-300)$ & $231.9(100-600)$ & $317.5(150-600)$ \\
\hline \multicolumn{7}{|l|}{ Allopurinol dose, $n(\%)$} \\
\hline$\leq 200 \mathrm{mg} /$ day & $13(92.9 \%)$ & $13(41.9 \%)$ & $5(10.4 \%)$ & $9(90 \%)$ & $25(62.5 \%)$ & $3(7.5 \%)$ \\
\hline > 200-300 mg/day & $1(7.1 \%)$ & $16(51.6 \%)$ & $33(68.8 \%)$ & $1(10 \%)$ & $13(32.5 \%)$ & $32(80 \%)$ \\
\hline > 300 mg/day & $0(0 \%)$ & $2(6.5 \%)$ & $10(20.8 \%)$ & $0(0 \%)$ & $2(5 \%)$ & $7(7.8 \%)$ \\
\hline $\begin{array}{l}\text { Presence of palpable } \\
\text { tophi, } n(\%)\end{array}$ & $10(71.4 \%)$ & $14(45.2 \%)$ & $22(45.8 \%)$ & $4(40 \%)$ & $13(32.5 \%)$ & $18(45 \%)$ \\
\hline \multicolumn{7}{|l|}{ Co-existing conditions, $n$ (\%) } \\
\hline Obesity $^{c}$ & $11(78.6 \%)$ & $23(74.2 \%)$ & $36(75 \%)$ & $8(80 \%)$ & $29(72.5 \%)$ & $27(67.5 \%)$ \\
\hline Kidney stones & $0(0 \%)$ & $1(3.2 \%)$ & $2(4.2 \%)$ & $1(10 \%)$ & $3(7.5 \%)$ & $1(2.5 \%)$ \\
\hline $\begin{array}{l}\text { Cardiovascular } \\
\text { disease }^{d}\end{array}$ & 13 (92.9\%) & $14(45.2 \%)$ & $11(22.9 \%)$ & $5(50 \%)$ & $26(65 \%)$ & $10(25 \%)$ \\
\hline Diabetes mellitus & $8(57.1 \%)$ & $12(38.7 \%)$ & $13(27.1 \%)$ & $7(70 \%)$ & $18(45 \%)$ & $4(10 \%)$ \\
\hline Hypertension & $11(78.6 \%)$ & $29(93.5 \%)$ & $25(52.1 \%)$ & $9(90 \%)$ & $36(90 \%)$ & $22(55 \%)$ \\
\hline Hyperlipidemia & $12(85.7 \%)$ & $19(61.3 \%)$ & $27(56.3 \%)$ & $7(70 \%)$ & $22(55 \%)$ & $18(45 \%)$ \\
\hline \multicolumn{7}{|c|}{ Concurrent medications, $n$ (\%) } \\
\hline Diuretic & $13(92.9)$ & $19(61.3 \%)$ & $11(22.9 \%)$ & $7(70 \%)$ & $23(57.5 \%)$ & $8(20.0 \%)$ \\
\hline Aspirin & $11(78.6 \%)$ & $17(54.8 \%)$ & $13(27.1 \%)$ & $7(70 \%)$ & $23(57.5 \%)$ & $10(25 \%)$ \\
\hline $\begin{array}{l}\text { Any anti-inflammatory } \\
\text { prophylaxis }\end{array}$ & $5(35.7 \%)$ & $15(48.4 \%)$ & $25(52.1 \%)$ & $4(40 \%)$ & $24(60 \%)$ & $23(57.5 \%)$ \\
\hline Colchicine & $2(14.3 \%)$ & $11(25.5 \%)$ & $22(45.8 \%)$ & $3(30 \%)$ & $13(32.5 \%)$ & $18(45 \%)$ \\
\hline NSAID & $0(0 \%)$ & $3(9.7 \%)$ & $6(12.5 \%)$ & $2(20 \%)$ & $4(10 \%)$ & $9(22.5 \%)$ \\
\hline Prednisone & $3(21.4 \%)$ & 8 (19.4\%) & $3(6.3 \%)$ & $1(10 \%)$ & 9 (22.5\%) & $2(5 \%)$ \\
\hline
\end{tabular}

$\mathrm{CrCL}$ creatinine clearance, NSAID non steroidal anti-inflammatory drug

${ }^{\mathrm{a}}$ Mean (SD)

${ }^{\mathrm{b}}$ Mean (range)

'Obesity defined as body mass index $\geq 30 \mathrm{~kg} / \mathrm{m}^{2}$

${ }^{\mathrm{d}}$ Cardiovascular disease defined as ischemic heart disease, heart failure or peripheral vascular disease 


\section{Results}

\section{Demographics}

There were 183 participants who entered the study; 93 in the control/DE group $(n=14$ with $\mathrm{CrCL}<30 \mathrm{ml} / \mathrm{min}$; $n=31$ with $\mathrm{CrCL} \geq 30$ to $<60 \mathrm{ml} / \mathrm{min} ; n=48$ with $\mathrm{CrCL}$ $\geq 60 \mathrm{ml} / \mathrm{min} \mathrm{48}$ ) and 90 in the DE/DE group ( $n=10$ with $\mathrm{CrCL}<30 \mathrm{ml} / \mathrm{min} ; n=40$ with $\mathrm{CrCL} \geq 30$ to $<60 \mathrm{ml} / \mathrm{min}$; $n=40$ with $\mathrm{CrCL} \geq 60 \mathrm{ml} / \mathrm{min}$ ). There were 143 participants who completed the month-12 visit; 73 in the control/DE group ( $n=8$ with $\mathrm{CrCL}<30 \mathrm{ml} / \mathrm{min} ; n=24$ with $\mathrm{CrCL} \geq 30$ to $<60 \mathrm{ml} / \mathrm{min} ; n=41$ with $\mathrm{CrCL} \geq 60 \mathrm{ml} /$ $\min )$ and 70 in the $\mathrm{DE} / \mathrm{DE}$ group $(n=7$ with $\mathrm{CrCL}$ $<30 \mathrm{ml} / \mathrm{min} ; n=35$ with $\mathrm{CrCL} \geq 30$ to $<60 \mathrm{ml} / \mathrm{min} ; n=$ 28 with $\mathrm{CrCL} \geq 60 \mathrm{ml} / \mathrm{min}$ ). There were 137 participants who completed the month-24 visit; 68 in the control/DE group ( $n=7$ with $\mathrm{CrCL}<30 \mathrm{ml} / \mathrm{min} ; n=22$ with $\mathrm{CrCL}$ $\geq 30$ to $<60 \mathrm{ml} / \mathrm{min} ; n=39$ with $\mathrm{CrCL} \geq 60 \mathrm{ml} / \mathrm{min}$ ) (73.1\%) and 69 in the DE/DE group ( $n=7$ with CrCL $<30 \mathrm{ml} / \mathrm{min} ; n=33$ with $\mathrm{CrCL} \geq 30$ to $<60 \mathrm{ml} / \mathrm{min} ; n=$ 29 with $\mathrm{CrCL} \geq 60 \mathrm{ml} / \mathrm{min}$ ). Demographics for each of the randomized groups according to baseline kidney function group are outlined in Table 1.
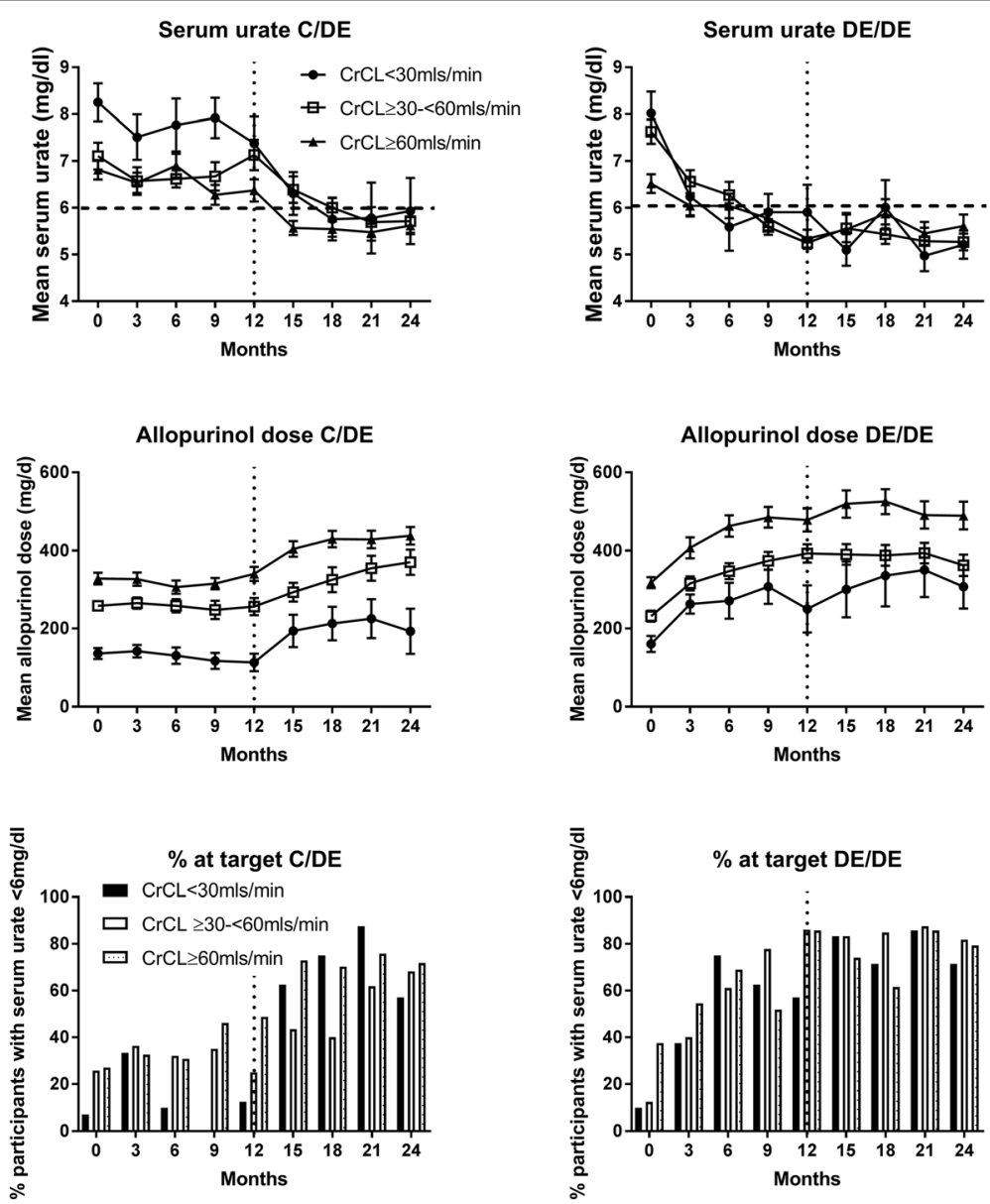

$\%$ change in SU C/DE
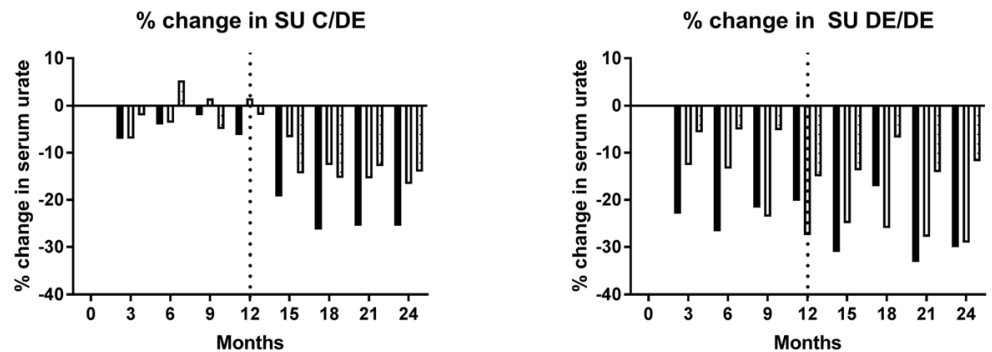

Fig. 1 Mean serum urate, time course for achieving target serum urate (SU), mean percentage change in SU over the 24-month study period and mean allopurinol dose in the control/dose escalation phase(C/DE) and immediate dose escalation (DE/DE) groups by kidney function group. The vertical line represents the start of the open-label extension phase of the study. $\mathrm{CrCL}$, creatinine clearance 
Table 2 Primary and secondary efficacy endpoints

\begin{tabular}{|c|c|c|c|c|c|c|c|}
\hline \multirow[t]{2}{*}{ Variable } & \multicolumn{3}{|l|}{ C/DE $(n=93)$} & \multicolumn{3}{|l|}{$\mathrm{DE} / \mathrm{DE}(n=90)$} & \multirow[t]{2}{*}{$P$ values $^{\mathrm{a}}$} \\
\hline & $\begin{array}{l}\mathrm{CrCL}<30 \mathrm{ml} / \\
\min (n=14)\end{array}$ & $\begin{array}{l}\mathrm{CrCL} \geq 30 \text { to } \\
<60 \mathrm{ml} / \mathrm{min} \\
(n=31)\end{array}$ & $\begin{array}{l}\mathrm{CrCL} \geq 60 \mathrm{ml} / \\
\min (n=48)\end{array}$ & $\begin{array}{l}\mathrm{CrCL}<30 \mathrm{ml} / \\
\min (n=10)\end{array}$ & $\begin{array}{l}\mathrm{CrCL} \geq 30 \text { to } \\
<60 \mathrm{ml} / \mathrm{min} \\
(n=40)\end{array}$ & $\begin{array}{l}\mathrm{CrCL} \geq 60 \mathrm{ml} / \\
\min (n=40)\end{array}$ & \\
\hline \multicolumn{8}{|l|}{ Change in serum urate $(\mathrm{mg} / \mathrm{dll})$, mean $(\mathrm{SE})$} \\
\hline Baseline to month 12 & $-0.67(0.67)$ & $-0.05(0.33)$ & $-0.25(0.26)$ & $-1.49(0.47)$ & $-2.27(0.29)$ & $-1.06(0.24)$ & 0.04 \\
\hline Baseline to month 24 & $-2.23(0.88)$ & $-1.41(0.36)$ & $-1.10(0.25)$ & $-2.47(0.68)$ & $-2.35(0.28)$ & $-0.86(0.27)$ & 0.15 \\
\hline Month 12 to month 24 & $-1.42(0.45)$ & $-1.51(0.41)$ & $-0.87(0.25)$ & $-1.20(0.29)$ & $0.01(0.17)$ & $0.34(0.23)$ & 0.82 \\
\hline \multicolumn{8}{|l|}{ Serum urate $<6 \mathrm{mg} / \mathrm{dl}, \%$} \\
\hline Month 12 & $13 \%$ & $25 \%$ & $49 \%$ & $57 \%$ & $86 \%$ & $86 \%$ & 0.50 \\
\hline Month 24 & $57 \%$ & $68 \%$ & $72 \%$ & $71 \%$ & $82 \%$ & $79 \%$ & 0.93 \\
\hline \multicolumn{8}{|l|}{ Mean (SE) serum urate } \\
\hline Baseline & $8.25(0.41)$ & $7.10(0.29)$ & $6.82(0.21)$ & $8.02(0.46)$ & $7.63(0.26)$ & $6.52(0.20)$ & $<0.001^{b}$ \\
\hline Month 12 & $7.38(0.57)$ & $7.13(0.32)$ & $6.37(0.24)$ & $5.91(0.59)$ & $5.25(0.12)$ & $5.34(0.19)$ & 0.20 \\
\hline Month 24 & $5.93(0.71)$ & $5.72(0.25)$ & $5.62(0.19)$ & $5.21(0.30)$ & $5.27(0.18)$ & $5.61(0.25)$ & 0.46 \\
\hline \multicolumn{8}{|c|}{ Percentage change in serum urate from baseline, mean (SE) } \\
\hline Baseline to month 12 & $-6.2(7.2)$ & $1.6(4.9)$ & $-1.9(3.4)$ & $-20.2(6.0)$ & $-27.5(2.9)$ & $-15.0(3.5)$ & 0.08 \\
\hline Baseline to month 24 & $-25.5(8.5)$ & $-16.6(4.8)$ & $-13.9(3.2)$ & $-30.0(5.8)$ & $-29.1(2.8)$ & $-11.8(4.1)$ & 0.14 \\
\hline Month 12 to month 24 & $-19.4(5.4)$ & $-17.9(4.6)$ & $-10.1(3.5)$ & $-2.4(5.4)$ & $0.87(3.2)$ & $7.75(4.6)$ & 0.99 \\
\hline \multicolumn{8}{|l|}{ Percentage with at least one flare in preceding month } \\
\hline Baseline & $50 \%$ & $38.7 \%$ & $56.3 \%$ & $40.0 \%$ & $32.5 \%$ & $42.5 \%$ & $0.17^{\mathrm{b}}$ \\
\hline Month 12 & $37.5 \%$ & $12.5 \%$ & $39 \%$ & $14.3 \%$ & $34.3 \%$ & $32.1 \%$ & 0.10 \\
\hline Month 24 & $14.3 \%$ & $13.6 \%$ & $20.5 \%$ & $0.0 \%$ & $15.2 \%$ & $3.4 \%$ & 0.30 \\
\hline $\begin{array}{l}\text { Allopurinol dose (mg/day) to achieve target SU at } \\
\text { month } 24 \text {, mean (range) }\end{array}$ & $\begin{array}{l}262.5 \\
(150-500)\end{array}$ & $\begin{array}{l}389.3 \\
(250-650)\end{array}$ & $\begin{array}{l}439.3 \\
(300-800)\end{array}$ & $\begin{array}{l}350.0 \\
(250-600)\end{array}$ & $\begin{array}{l}396.3 \\
(200-700)\end{array}$ & $\begin{array}{l}491.3 \\
(300-900)\end{array}$ & $0.002^{\mathrm{b}}$ \\
\hline $\begin{array}{l}\text { Number of participants requiring }>300 \mathrm{mg} / \text { day to } \\
\text { achieve target SU at month } 24\end{array}$ & $1 / 4(25 \%)$ & $\begin{array}{l}9 / 14 \\
(64.3 \%)\end{array}$ & $\begin{array}{l}20 / 28 \\
(71.4 \%)\end{array}$ & $\begin{array}{l}1 / 5 \\
(20 \%)\end{array}$ & $\begin{array}{l}16 / 27 \\
(59.3 \%)\end{array}$ & $\begin{array}{l}19 / 23 \\
(82.6 \%)\end{array}$ & 0.013 \\
\hline \multicolumn{8}{|c|}{ Percentage of individuals receiving anti-inflammatory prophylaxis } \\
\hline Baseline & $35.7 \%$ & $48.4 \%$ & $52.1 \%$ & $40.0 \%$ & $60.0 \%$ & $57.5 \%$ & $0.30^{\mathrm{b}}$ \\
\hline Month 12 & $37.5 \%$ & $29.2 \%$ & $29.3 \%$ & $71.4 \%$ & $34.3 \%$ & $14.3 \%$ & 0.15 \\
\hline Month 24 & $14.3 \%$ & $18.2 \%$ & $15.4 \%$ & $57.1 \%$ & $9.1 \%$ & $10.3 \%$ & 0.16 \\
\hline \multicolumn{8}{|l|}{ HAQ mean (SE) change } \\
\hline Baseline to month 12 & $-0.10(0.19)$ & $0.10(0.15)$ & $-0.14(0.09)$ & $0.47(0.28)$ & $0.06(0.12)$ & $-0.13(0.11)$ & 0.25 \\
\hline Baseline to month 24 & $-0.09(0.21)$ & $0.14(0.11)$ & $-0.32(0.07)$ & $-0.19(0.30)$ & $-0.05(0.11)$ & $-0.20(0.12)$ & 0.67 \\
\hline Month 12 to month 24 & $0.10(0.04)$ & $-0.09(0.18)$ & $-0.22(0.08)$ & $-0.72(0.35)$ & $-0.05(0.13)$ & $-0.05(0.11)$ & 0.04 \\
\hline \multicolumn{8}{|l|}{ Pain VAS mean (SE) change } \\
\hline Baseline to month 12 & $-0.25(0.90)$ & $1.04(0.51)$ & $-0.02(0.40)$ & $0.43(0.61)$ & $0.17(0.40)$ & $-0.43(0.54)$ & 0.57 \\
\hline Baseline to month 24 & $-1.15(1.3)$ & $0.27(0.62)$ & $-1.10(0.35)$ & $-0.50(1.36)$ & $-0.64(0.37)$ & $-1.28(0.53)$ & 0.56 \\
\hline Month 12 to month 24 & $-0.71(0.71)$ & $-0.52(0.84)$ & $-1.03(0.37)$ & $-0.60(0.87)$ & $-0.67(0.34)$ & $-0.78(0.57)$ & 0.93 \\
\hline \multicolumn{8}{|l|}{ SJC mean (SE) change } \\
\hline Baseline to month 12 & $-2.88(1.84)$ & $-0.04(1.05)$ & $-0.07(0.72)$ & $0.86(1.6)$ & $-1.17(0.89)$ & $0.17(0.53)$ & 0.19 \\
\hline Baseline to month 24 & $-2.14(1.39)$ & $-2.86(1.65)$ & $-1.26(0.73)$ & $-0.67(0.67)$ & $-1.85(0.93)$ & $-0.24(0.27)$ & 0.99 \\
\hline Month 12 to month 24 & $1.23(1.16)$ & $-2.91(2.24)$ & $-1.34(0.98)$ & $0(0)$ & $-0.52(0.42)$ & $-0.37(0.59)$ & 0.57 \\
\hline \multicolumn{8}{|l|}{ TJC mean (SE) change } \\
\hline Baseline to month 12 & $2.13(3.56)$ & $0.04(1.33)$ & $-2.83(1.07)$ & $-0.57(0.62)$ & $-1.57(0.90)$ & $1.18(1.42)$ & 0.04 \\
\hline Baseline to month 24 & $-2.57(1.97)$ & $-1.73(1.49)$ & $-2.08(0.88)$ & $-0.50(0.34)$ & $-0.42(1.54)$ & $-0.97(0.50)$ & 0.97 \\
\hline Month 12 to month 24 & $-5.0(3.0)$ & $-2.57(1.83)$ & $0.65(0.55)$ & $-0.20(0.20)$ & $1.18(1.32)$ & $-1.96(1.37)$ & 0.02 \\
\hline
\end{tabular}

$C / D E$ control/dose escalation phasegroup, $D D$ immediate dose escalation group, $C r C L$ creatinine clearance, $S U$ serum urate, $H A Q$ health assessment questionnaire, VAS visual analogue scale, SJC swollen joint count, $T J C$ tender joint count

${ }^{\text {a }}$ For levels and changes after baseline the $p$ value tests the significance of randomization depending on baseline $\mathrm{CrCL}$

${ }^{\mathrm{b}}$ For baseline assessments the $p$ value represents the significance of differences between kidney function groups 


\section{Serum urate}

In both the control/DE and DE/DE groups the mean baseline SU was significantly higher in those with $\mathrm{CrCL}<30 \mathrm{ml} /$ min compared to those with $\mathrm{CrCL} \geq 30$ to $<60 \mathrm{ml} / \mathrm{min}$ and $\geq 60 \mathrm{ml} / \mathrm{min}$ (Fig. 1a). Mean SU was below $6 \mathrm{mg} / \mathrm{dl}$ in all kidney function groups by month 24 (Fig. 1a). The percentage with $\mathrm{SU}<6 \mathrm{mg} / \mathrm{dl}$ at the final visit by randomization and by kidney function groups is shown in Fig. 1b. Irrespective of randomization, there was no significant difference in the percentage of those with $\mathrm{CrCL}<30 \mathrm{ml} / \mathrm{min}$ who achieved $\mathrm{SU}<6 \mathrm{mg} / \mathrm{dl}$ at the final visit compared to those with $\mathrm{CrCL} \geq 30$ to $<60 \mathrm{ml} / \mathrm{min}$ and $\geq 60 \mathrm{ml} / \mathrm{min}$, with percentages of $64.3 \%$ vs. $76.4 \%$ vs. $75.0 \%$, respectively ( $p=$ $0.65)$. The mean (standard error (SE)) change in SU from baseline to month 24 irrespective of randomization, was significantly higher in those with $\mathrm{CrCL}<30 \mathrm{mls} / \mathrm{min}$; mean change $-2.23(0.88) \mathrm{mg} / \mathrm{dl}$ in those with $\mathrm{CrCL}<30 \mathrm{mls} / \mathrm{min}$, $-1.98(0.23) \mathrm{mg} / \mathrm{dl}$ in those with $\mathrm{CrCL} \geq 30$ to $<60 \mathrm{ml} / \mathrm{min}$ and $-1.00(0.79) \mathrm{mg} / \mathrm{dl}$ in those with $\mathrm{CrCL} \geq 60 \mathrm{ml} / \mathrm{min}(p=$ 0.002 ). The mean change in SU by kidney function and randomization group is shown in Table 2.

The mean percentage change in $\mathrm{SU}$ by randomization and by kidney function groups is shown in Fig. 1c. Irrespective of randomization, the mean (SE) percentage change in SU from baseline to final visit in those with $\mathrm{CrCL}<30 \mathrm{ml} / \mathrm{min}$ was similar to those with $\mathrm{CrCL} \geq 30$ to $<60 \mathrm{ml} / \mathrm{min}$ and significantly higher than those with CrCL $\geq 60 \mathrm{ml} / \mathrm{min}(-27.7 \%(5.0 \%)$ vs. $-24.1 \%(2.7 \%)$ vs. $-13.0 \%$ $(2.5 \%)(p=0.003))$.

\section{Allopurinol dose}

Mean allopurinol dose during the study period by randomization and by kidney function groups is shown in Fig. 1d. Irrespective of randomization, mean (SE) allopurinol dose at baseline was lower in those with lower CrCL; 146 (18) mg/day, 243 (10) mg/day and 323 (9) $\mathrm{mg} /$ day $(p<0.001)$ in those with $\mathrm{CrCL}$ $<30 \mathrm{mls} / \mathrm{min}, \geq 30$ to $<60 \mathrm{ml} / \mathrm{min}$ and $\geq 60 \mathrm{ml} / \mathrm{min}$, respectively. Irrespective of randomization, the mean (SE) allopurinol dose at month 24 was significantly lower in those with $\mathrm{CrCL}<30 \mathrm{ml} / \mathrm{min}$ as compared to those with $\mathrm{CrCL} \geq 30$ to $<60 \mathrm{ml} / \mathrm{min}$ or $\mathrm{CrCL}$ $\geq 60 \mathrm{ml} / \mathrm{min}$ (250 (43) mg/day, 365 (22) $\mathrm{mg} /$ day and 460 (19) $\mathrm{mg} /$ day, respectively $(p<0.001))$. Allopurinol dose in those with $\mathrm{SU}<6 \mathrm{mg} / \mathrm{dl}$ at month 24 is shown in Fig. 2.

The allopurinol dose required to achieve target SU was associated with baseline kidney function (Table 2). Of those with $\mathrm{CrCL}<30 \mathrm{ml} / \mathrm{min}$ ( $\mathrm{n}=14$ ), only one participant in the control/DE and one in the DE/DE group required $>300 \mathrm{mg} /$ day to achieve target SU. In those with higher $\mathrm{CrCL}$, the number of participants requiring $>300 \mathrm{mg} /$ day allopurinol to achieve target SU was higher (Table 2). Irrespective of randomization, the mean (range) allopurinol dose required to achieve target $\mathrm{SU}$ was higher in those with better kidney function (311.1 mg/day (150-600) vs. $393.9 \mathrm{mg} /$ day (200-700) vs. $462.8 \mathrm{mg} /$ day (300-900)).

\section{Adverse events}

There were 17 deaths during the study period, details of these have been published previously $[10,11]$. During the RCT phase of the study there were five deaths in the control group of which four occurred in those with CrCL $<30 \mathrm{mls} / \mathrm{min}$. In comparison none of the five deaths in the dose escalation groups had a $\mathrm{CrCL}<30 \mathrm{ml} / \mathrm{min}$ (Fig. 3). During the open extension phase of the study there were four deaths in the control/DE group, of which one occurred in those with $\mathrm{CrCL}<30 \mathrm{mls} / \mathrm{min}$. In comparison, there were three deaths in the DE/DE group, of which one occurred in those with $\mathrm{CrCL}<30 \mathrm{mls} / \mathrm{min}$. Of note there were high rates of co-morbidities and in particular cardiovascular disease at baseline in those with $\mathrm{CrCL}<30 \mathrm{ml} /$ min (Table 1). The number of SAEs according to kidney function group and randomization group are shown in Table 3. The type and number of SAEs was as expected and was similar between groups. The percentage of participants with treatment emergent or worsening gamma glutamyl transferase (GGT), alanine transaminase (ALT), aspartate aminotransferase (AST), alkaline phosphatase (ALP), creatinine and CrCL by kidney function groups are shown in Fig. 3.

\section{Discussion}

Long-term urate lowering in the setting of CKD is challenging and controversial. Although allopurinol is considered first-line ULT, there are limited data in those with CKD. Herein, we showed that use of allopurinol is safe and effective even in those with CKD.

There are few treatment options for urate lowering in people with stage 4 and 5 CKD and gout. There are limited data on the use of febuxostat in those with CrCL $<30 \mathrm{ml} / \mathrm{min}$ [13]; uricosuric agents are either contraindicated or not effective in those with $\mathrm{CrCL}<30 \mathrm{mls} / \mathrm{min}$, and while pegloticase needs no dose adjustment in CKD, it is not widely available [14]. Thus it is important that

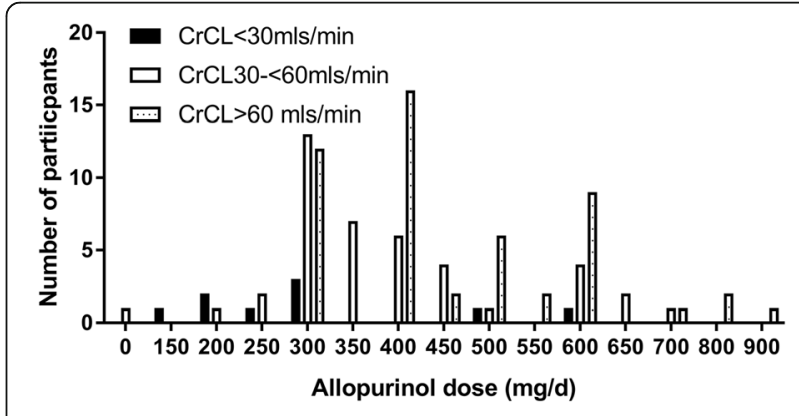

Fig. 2 Allopurinol dose at month 24 in those with serum urate $<6$ mg/ dl. $\mathrm{CrCl}$, creatinine clearance 
a

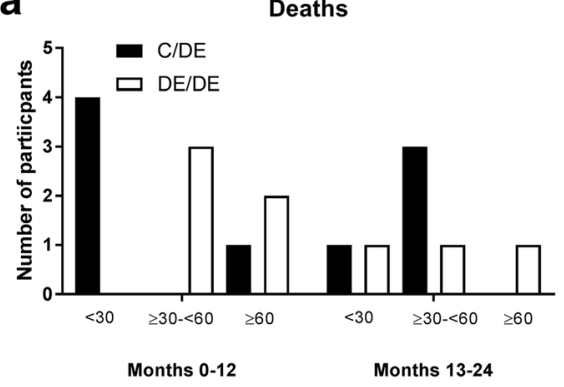

C

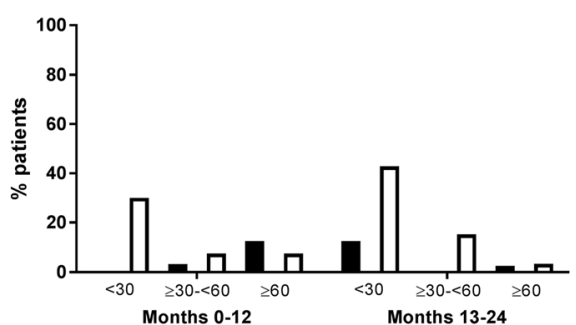

e

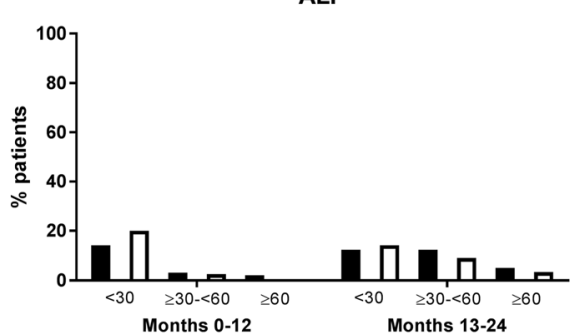

g

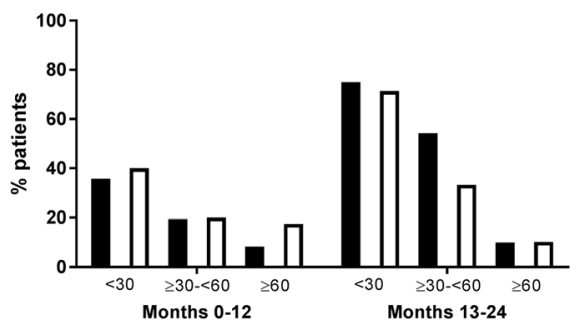

b

GGT

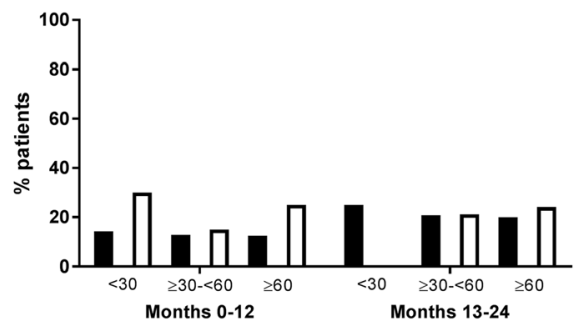

d

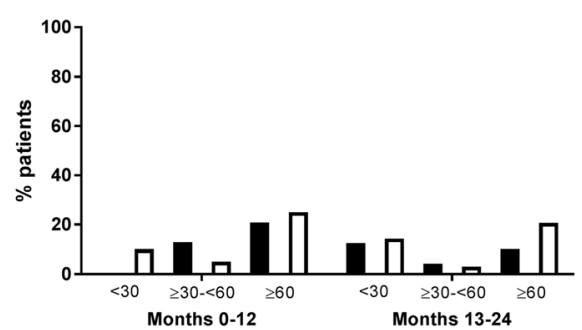

$\mathbf{f}$

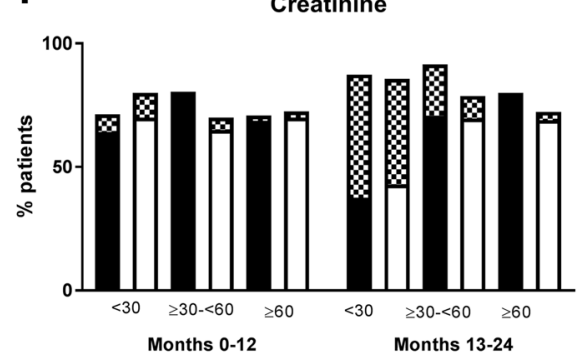

h

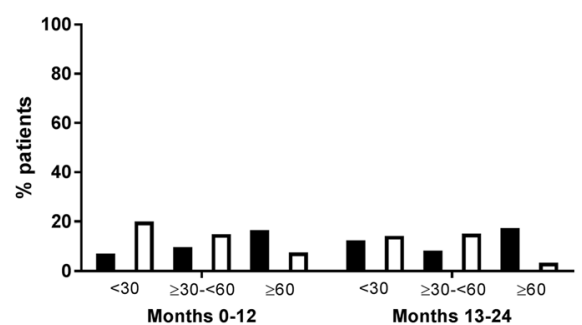

Fig. 3 Deaths and treatment-emergent or worsening laboratory adverse events (AEs): number of individuals with at least one AE over the 24-month study period by kidney function groups in the dose escalation phase (control/DE) and immediate dose escalation (DE/DE) groups. a Deaths. b-e Liver function. $\mathbf{f}$ Percentage of participants with increase in creatinine from baseline (solid bars, C/DE; open bars, DE/DE, Common Terminology Criteria for Adverse Events (CTCAE) grade 1. Hatched area indicates CTCAE grade 2). g, h Percentage of participants with $>20 \%$ decrease (worsening) (g) or increase (improvement) (h) in creatinine clearance (CrCL) from baseline. GGT, gamma glutamyl transferase; AST aspartate aminotransferase; ALT, alanine transaminase; ALP, alkaline phosphatase

clinicians can safely and effectively use allopurinol, given its widespread availability and low cost.

In the current study, similar proportions of participants in each kidney function group achieved target urate, suggesting the strategy is effective even in those with more severe $C K D$. The dose required to achieve target $\mathrm{SU}$ in those with $\mathrm{CrCL}<30 \mathrm{ml} / \mathrm{min}$ was $\leq 300 \mathrm{mg} /$ day in the majority of participants. Doses $>300 \mathrm{mg} /$ day are only infrequently used in clinical practice even in those with normal kidney function, frequently due to physician inertia or concern about dose escalation $[2,15]$. The data presented herein suggest that in people with $\mathrm{CrCL}<30 \mathrm{ml} / \mathrm{min}$, 
Table 3 Serious adverse events during months $0-12$ and months $13-24$ by kidney function group

\begin{tabular}{|c|c|c|c|c|c|c|c|}
\hline \multirow[t]{2}{*}{ CTCAE category } & \multirow[t]{2}{*}{ Time period } & \multicolumn{3}{|l|}{ Control $(n=93)$} & \multicolumn{3}{|c|}{ Dose escalation $(n=90)$} \\
\hline & & $\begin{array}{l}\mathrm{CrCL}<30 \mathrm{ml} / \mathrm{min} \\
(n=14)\end{array}$ & $\begin{array}{l}\mathrm{CrCL} \geq 30 \text { to } \\
<60 \mathrm{ml} / \mathrm{min} \\
(n=31)\end{array}$ & $\begin{array}{l}\mathrm{CrCL} \geq 60 \mathrm{ml} / \mathrm{min} \\
(n=48)\end{array}$ & $\begin{array}{l}\mathrm{CrCL}<30 \mathrm{ml} / \mathrm{min} \\
(n=10)\end{array}$ & $\begin{array}{l}\mathrm{CrCL} \geq 30 \text { to } \\
<60 \mathrm{ml} / \mathrm{min} \\
(n=40)\end{array}$ & $\begin{array}{l}\mathrm{CrCL} \\
\geq 60 \mathrm{ml} / \mathrm{min} \\
(n=40)\end{array}$ \\
\hline \multirow[t]{2}{*}{ Cardiac disorders } & Month 0-12 & $6(3)$ & $7(4)$ & $1(1)$ & $1(1)$ & $9(7)$ & $4(3)$ \\
\hline & Month 13-24 & $3(2)$ & $8(5)$ & 0 & 0 & $6(5)$ & $2(2)$ \\
\hline \multirow[t]{2}{*}{ Gastrointestinal disorders } & Month 0-12 & $1(1)$ & $3(3)$ & $2(2)$ & 0 & $3(3)$ & 0 \\
\hline & Month 13-24 & 0 & $5(4)$ & $1(1)$ & 0 & $3(3)$ & 0 \\
\hline \multirow[t]{2}{*}{ General disorders } & Month 0-12 & $1(1)$ & 0 & 0 & 0 & 0 & $1(1)$ \\
\hline & Month 13-24 & $1(1)$ & 0 & $1(1)$ & 0 & 0 & $1(1)$ \\
\hline \multirow[t]{2}{*}{ Hepatobiliary disorders } & Month 0-12 & 0 & 0 & 0 & 0 & $1(1)$ & 0 \\
\hline & Month 13-24 & 0 & 0 & 0 & 0 & 0 & 0 \\
\hline \multirow[t]{2}{*}{ Infections and infestations } & Month 0-12 & $2(2)$ & $3(3)$ & $3(3)$ & $1(1)$ & $2(1)$ & $1(1)$ \\
\hline & Month 13-24 & 0 & $6(4)$ & $2(2)$ & $3(3)$ & $5(3)$ & $1(1)$ \\
\hline \multirow{2}{*}{$\begin{array}{l}\text { Injury, poisoning and procedural } \\
\text { complications }\end{array}$} & Month 0-12 & $1(1)$ & 0 & $1(1)$ & 0 & $1(1)$ & 0 \\
\hline & Month 13-24 & $1(1)$ & $3(2)$ & $1(1)$ & 0 & $1(1)$ & 0 \\
\hline \multirow[t]{2}{*}{ Investigations } & Month 0-12 & 0 & 0 & 0 & 0 & $1(1)$ & 0 \\
\hline & Month 13-24 & 0 & 0 & 0 & 0 & 0 & 0 \\
\hline \multirow[t]{2}{*}{ Metabolism and nutrition } & Month 0-12 & 0 & 0 & 0 & $1(1)$ & $1(1)$ & 0 \\
\hline & Month 13-24 & 0 & 0 & 0 & 0 & 0 & 0 \\
\hline \multirow[t]{2}{*}{ Musculoskeletal } & Month 0-12 & 0 & 0 & $1(1)$ & $1(1)$ & 0 & 0 \\
\hline & Month 13-24 & 0 & 0 & $2(1)$ & 0 & $1(1)$ & 0 \\
\hline \multirow[t]{2}{*}{ Nervous system disorders } & Month 0-12 & $1(1)$ & $1(1)$ & $1(1)$ & 0 & 0 & $1(1)$ \\
\hline & Month 13-24 & $3(2)$ & 0 & 0 & $1(1)$ & $3(3)$ & 0 \\
\hline \multirow[t]{2}{*}{ Renal and urinary disorders } & Month 0-12 & $3(3)$ & $2(2)$ & 0 & $1(1)$ & $1(1)$ & 0 \\
\hline & Month 13-24 & 0 & 0 & 0 & $2(2)$ & $1(1)$ & 0 \\
\hline \multirow{2}{*}{$\begin{array}{l}\text { Respiratory, thoracic and } \\
\text { mediastinal disorders }\end{array}$} & Month 0-12 & 0 & $1(1)$ & $1(1)$ & $1(1)$ & $1(1)$ & 0 \\
\hline & Month 13-24 & 0 & 0 & 0 & 0 & 0 & 0 \\
\hline \multirow{2}{*}{$\begin{array}{l}\text { Skin and subcutaneous tissue } \\
\text { disorders }\end{array}$} & Month 0-12 & $1(1)$ & 0 & 0 & 0 & 0 & $2(1)$ \\
\hline & Month 13-24 & 0 & 0 & 0 & 0 & 0 & 0 \\
\hline \multirow[t]{2}{*}{ Psychiatric disorders } & Month 0-12 & 0 & 0 & 0 & 0 & 0 & 0 \\
\hline & Month 13-24 & $1(1)$ & 0 & 0 & 0 & 0 & $1(1)$ \\
\hline \multirow[t]{2}{*}{ Vascular disorders } & Month 0-12 & 0 & 0 & 0 & 0 & 0 & 0 \\
\hline & Month 13-24 & 0 & 0 & 0 & 0 & $1(1)$ & 0 \\
\hline
\end{tabular}

Data reported are number of events (number of individuals)

allopurinol doses $>300 \mathrm{mg} /$ day are rarely needed to achieve target SU.

The numbers and types of SAEs were similar in both groups but as expected the number of cardiac events was higher in those with $\mathrm{CrCL}<30 \mathrm{ml} / \mathrm{min}$ even during the first 12 months when dose escalation was not undertaken [16]. While a number of abnormalities in kidney function were noted, they were similar between randomized groups over the study period.

There are several limitations to this study. There were only small numbers of participants with $\mathrm{CrCL}<30 \mathrm{ml} /$ min and the study was not powered to detect the rare
AHS. Further adequately powered studies of people with stage 4/5 CKD may be required to clarify the impact on clinical outcomes such as flares, activity limitation and health-related quality of life, and to confirm the safety of this approach. However, studies of sufficient size to detect the rare AHS are unlikely to be undertaken given the large numbers of participants that would be required.

\section{Conclusion}

Allopurinol is effective at lowering urate even in those with severe CKD. The dose required to achieve target SU is higher in those with better kidney function. Accepting 
that there were small numbers of participants with $\mathrm{CrCL}$ $<30 \mathrm{ml} / \mathrm{min}$, these data indicate that allopurinol dose escalation to target $\mathrm{SU}$ is safe in people with CKD.

\author{
Abbreviations \\ ACR: American College of Rheumatology; AE: Adverse event; AHS: Allopurino \\ hypersensitivity syndrome; ALP: Alkaline phosphatase; ALT: Alanine \\ transaminase; ANOVA: Analysis of variance; AST: Aspartate aminotransferase; \\ CKD: Chronic kidney disease; control/DE: Dose escalation phase group; \\ CrCL: Creatinine clearance; CTCAE: Common Terminology Criteria for Adverse \\ Events; DE/DE: Immediate dose escalation group; EULAR: European League \\ Against Rheumatism; GGT: Gamma glutamyl transferase; HAQ: Health \\ assessment questionnaire; N: Number; NSAID: Non steroidal anti- \\ inflammatory drug; SAE: Serious adverse event; SD: Standard deviation; \\ SE: Standard error; SJC: Swollen joint count; SU: Serum urate; TJC: Tender \\ joint count; ULT: Urate lowering therapy; VAS: Visual analogue scale
}

\section{Acknowledgements}

We are grateful to the Health Research Council of New Zealand Independent Data Safety Monitoring Committee for monitoring the study.

\section{Funding}

This study was funded by the Health Research Council of New Zealand.

\section{Availability of data and materials}

The datasets used and/or analyzed during the current study are available from the corresponding author on reasonable request.

\section{Authors' contributions}

LS: literature search, study design, data collection, data analysis, data interpretation, manuscript preparation. PC: study design, data collection, data analysis, data interpretation, manuscript preparation. MB: study design, data analysis, data interpretation, manuscript preparation. $\mathrm{AH}$ : data collection, data analysis, data interpretation, manuscript preparation. CF: study design, data analysis, data interpretation, manuscript preparation. PT: data collection, data analysis, data interpretation, manuscript preparation. JD: study design, data collection, data analysis, data interpretation, manuscript preparation. ND: literature search, study design, data collection, data analysis, data interpretation, manuscript preparation. All authors read and approved the final manuscript.

\section{Ethics approval and consent to participate}

Ethical approval was obtained from the Multi-Regional Ethics Committee, New Zealand. Written informed consent was obtained from each participant.

\section{Consent for publication}

Not applicable.

\section{Competing interests}

Prof. Stamp reports grants from Health Research Council of New Zealand, outside the conduct of the study; grants from Ardea Biosciences, grants from Health Research Council of the submitted work; Dr. Chapman has nothing to disclose; Prof. Barclay has nothing to disclose; Dr Horne reports grants from Health Research Council of New Zealand, during the conduct of the study; Prof. Frampton has nothing to disclose; Mrs. Drake has nothing to disclose; Mr Tan has nothing to disclose; Prof. Dalbeth reports grants from Health Research Council of New Zealand, during the conduct of the study, grants from Health Research Council of New Zealand, grants and personal fees from AstraZeneca, grants and personal fees from Ardea Biosciences, personal fees from Takeda, personal fees from Teijin, personal fees from Menarini, grants from Fonterra, personal fees from Pfizer, personal fees from Crealta and personal fees from Cymabay, outside the submitted work.

\section{Publisher's Note}

Springer Nature remains neutral with regard to jurisdictional claims in published maps and institutional affiliations.

\section{Author details}

'Department of Medicine, University of Otago, Christchurch, P. O. Box 4345, Christchurch 8140, New Zealand. 'Department of Rheumatology, Immunology and Allergy, Christchurch Hospital, Private Bag 4710, Christchurch 8140, New Zealand. ${ }^{3}$ Department of Medicine, University of Auckland, Private Bag 92019, Auckland, New Zealand.

Received: 17 August 2017 Accepted: 1 December 2017

Published online: 21 December 2017

\section{References}

1. Khanna D, Fitzgerald J, Khanna P, Sangmee B, Singh M, Neogi T, Pillinger M, Merill J, Lee S, Prakash S, et al. 2012 American College of Rheumatology guidelines for the management of gout. Part 1: Systematic nonpharmacologic and pharmacologic therapeutic approaches to hyperuricaemia. Arthritis Care Res. 2012;64(10):1431-46.

2. Richette P, Doherty M, Pascual E, Barskova V, Becce F, Castaneda-Sanabria J, Coyfish M, Guillo S, Janesen T, Janssens H, et al. 2016 updated EULAR evidence-based recommendations for the management of gout. Ann Rheum Dis. 2017;76(1):29-42.

3. Hande K, Noone R, Stone W. Severe allopurinol toxicity. Description and guidelines for prevention in patients with renal insufficiency. Am J Med. 1984;76:47-56.

4. Stamp L, Day R, Yun J. Allopurinol hypersensitivity: investigating the cause and minimizing the risk. Nat Rev Rheum. 2016;12(4):235-42.

5. Stamp L, Taylor W, Jones P, Dockerty J, Drake J, Frampton C, Dalbeth N. Starting dose, but not maximum maintenance dose, is a risk factor for allopurinol hypersensitivity syndrome: a proposed safe starting dose of allopurinol. Arthritis Rheum. 2012;64(8):2529-36.

6. Chung W-H, Chang W-C, Stocker S, Juo C-G, Graham G, Lee M-H, Williams KM, Tian YC, Juan KC, Jan Wu YJ, Yang C-H, et al. Insights into the poor prognosis of allopurinol-induced severe cutaneous adverse reactions: the impact of renal insufficiency, high plasma levels of oxypurinol and granulysin. Ann Rheum Dis. 2015;74(12):2157-64.

7. Becker M, Schumacher HR, Wortmann R, MacDonald P, Eustace D, Palo W, Streit J, Joseph-Ridge N. Febuxostat compared with allopurinol in patients with hyperuricaemia and gout. N Engl J Med. 2005;353:2450-61.

8. Sundy J, Baraf H, Yood R, Edwards N, Gutierrez-Urena S, Treadwell E, Vázquez-Mellado J, White W, Lipsky P, Horowitz Z, et al. Efficacy and tolerability of pegloticase for the treatment of chronic gout in patients refractory to conventional treatment: two randomized controlled trials. JAMA. 2011;306(7):711-20.

9. Saag K, Fitz-Patrick D, Kopicko J, Fung M, Bhakta N, Adler S, Storgard C, Baumgartner S, Becker M. Lesinurad combined with allopurinol: randomized, double-blind, placebo-controlled study in gout subjects with inadequate response to standard of care allopurinol (a US-based study). Arthritis Rheum. 2017;69(1):203-12.

10. Stamp L, Chapman P, Barclay M, Horne A, Frampton C, Tan P, Drake J, Dalbeth N. A randomised controlled trial of the efficacy and safety of allopurinol dose escalation to achieve target serum urate in people with gout. Ann Rheum Dis. 2017;76:1522-8.

11. Stamp L, Chapman P, Barclay M, Horne A, Frampton C, Tan P, Drake J, Dalbeth N. Allopurinol dose escalation to achieve serum urate below $6 \mathrm{mg} /$ dl: an open label extension study. Ann Rheum Dis. 2017;76(12):2065-70.

12. Wallace S, Robinson H, Masi A, Decker J, McCarty D, Yu T. Preliminary criteria for the classification of the acute arthritis of primary gout. Arthritis Rheum. 1977;20(3):895-900.

13. Saag $K$, Whelton A, Becker M, MacDonald P, Hunt B, Gunawardhana L. Impact of febuxostat on renal function in gout subjects with moderate-tosevere renal impairment. Arthritis Rheum. 2016;68(8):2035-43.

14. Vargas-Santos $A B$, Neogi T. Management of gout and hyperuricaemia in CKD. Am J Kidney Dis. 2017. https://doi.org/10.1053/j.ajkd.2017.01.055.

15. Becker M, Fitz-Patrick D, Choi H, Dalbeth N, Storgarde C, Cravetsf M, Baumgartner S. An open-label, 6-month study of allopurinol safety in gout: the LASSO study. Semin Arthritis Rheum. 2015;2015(45):174-83.

16. Gupta T, Harikrishnan P, Kolte D, Khera S, Subramanian K, Mujib M, Masud A, Palaniswamy C, Sule S, Jain D, et al. Trends in management and outcomes of ST-elevation myocardial infarction in patients with end-stage renal disease in the United States. Am J Cardiol. 2015;115(8):1033-41. 